\title{
THE COMMUNITY CHALLENGE: THE LEARNING RESPONSE
}

\section{Genesis}

\section{Richard Bawden ${ }^{1]}$}

In this presentation I intend to narrate a story that has its particular origins in three strategic decisions collectively taken, almost twenty years ago now, by a small group of educators within a small agricultural polytechnic located on the urban/rural fringe of Australia's largest city. It is a story which arises out of the integrated thoughts and actions of an academic community, which, tired of its marginal status, decided in the late 1970s, to profoundly and concurrently transform itself as a School of Agriculture in three fundamental ways: (a) to change its own focus from production agriculture to responsible rural development, (b) to change its own emphasis from a teaching approach based on courses to one of learning based on projects, and (c) to change its own prevailing reductionist paradigm to embrace an holistic one. The mission became one of helping people in rural communities across the state, to learn their way forward to better futures, in the face of the immensely complex, dynamic, and slowly degrading environments, Socio-economic, politico-cultural and bio-physical, in which they increasingly recognised they were deeply embedded. The intent would thus become that of helping people to see their worlds differently as a prelude for doing things differently - essentially more systemically. The context for this grand enterprise is captured in the aphorism "if we always see how we've always seen, we'll always be who we've always been"! Changing the way we collectively construe ourselves means collectively changing the way we think about ourselves, to lead in turn, to changing the way we collectively act.

In this manner, we, as faculty at Hawkesbury Agricultural College, committed ourselves to helping in the facilitation of the development of learning communities across rural Australia, through the direct involvement of our students and ourselves, in collaborative learning projects with members of rural families and communities. As faculty and students alike, we would learn how to become a learning community of scholar practitioners, through our active participation in other emerging learning communities, and critical reflection upon those engagements.

Together we would learn how to see the world differently, and in the process, discover just how difficult a transformation this is, for individuals and the community both.

Many of the details of the journey which has ensued to date at Hawkesbury following those essential decisions, including both theoretical and practical details of the evolution of the processes of curriculum reform, of community outreach, of research, and of the organisation itself, have already been told elsewhere (cf Bawden et al 1984, Bawden 1992, Bawden and Packham 1993). What has not yet been clearly described or explained however, are recent developments in the model of the learning process which is central to the whole endeavour of what can now be referred to as, systemic development. This is the praxis involved in bringing abstract 'systems ideas' to bear to help inform actions to deal with events which are being experienced in the concrete world; and vice-versa, with systems ideas being generated out of the process of critical reflections on both the events themselves, and the actions which are being used to deal with them, which includes the process itself - the systemic development of systemic development, if you will, in which the metaphor of the community as a critical learning system is privileged.

\footnotetext{
${ }^{1}$ Director of the Centre for Systemic Development, University of Western Sydney Hawkesbury Richmond NSW 2753 Australia
}

Invited Plenary Paper: 29th Annual International Meeting of the Community Development Society. Athens Georgia 27-30th July 1997 
This presentation provides an opportunity then not just to give an update on the model of critical learning systems, but more importantly, to illustrate the manner by which that model is being both generated and used in practice in the creation of learning communities.

\section{A Word about Systems}

It is important to emphasise here that the word system as it is used in the present context, has a particular conceptual meaning, which is distinct from the rather woolly way that the word is often used in everyday conversation. Thus in contrast to the loose metaphoric images which are conjured up with talk of transport systems or information systems or health systems, critical learning systems reflect the notion of formal entities with particular structures and properties. To the systems theorist, a system is an organised, coherent, whole entity, which has, or can be assumed to have, properties which are unique to it as a whole entity. More formally stated "a system is a group of interacting components (subsystems) that conserves some identifiable set of relations with the sum of the components plus their relations (i.e., the system itself) conserving some identifiable set of relations to other entities (including other systems) (Laszlo and Laszlo 1997). In other words, when the component parts of a system interact together within the boundary of that system, the process results in the emergence of properties which are different from the mere additive effects of those parts, and unique to that particular system - the system is different from the sum of its parts. Moreover, as each component part of a system is also a 'lower order' (sub)system itself, and each system is, in turn, a subsystem of a 'higher order' (supra)system, unique and quite unpredictable properties emerge at a number of different levels of order within what is envisaged as a hierarchy of systems embedded within other systems. When we talk of the environment of a system, we are actually talking of a higher order system in which it is embedded. Systems are systems within systems within systems etc.

It also follows from this logic that each subsystem within a system must be different from all of the others in that system; so different indeed, that a 'tension of difference' exists between them. Subsystems not only influence each other through their interactions, but it is these interactions which create the whole. The whole is different from the sum of its parts because of what von Bertalanffy (1968) termed "the glorious unity of opposites".

The notion of wholeness through 'tensions of difference' is absolutely central to the usefulness of the critical learning systems approach to community development.

From this it is clear that each subsystem must also be significantly different from the system as whole, yet have the potential to influence and be influenced by it. As Ackoff (1981) sees this: each subsystem has an effect on the functioning of the whole, while each is also affected by at least one other subsystem within the whole. These principles of diversity and what is termed 'requisite variety', are also central to the concept of critical learning systems. Finally, systems can only retain their coherence within and across these embedded hierarchies through cybernetic networks of feedback communication and control. The stability of systems is maintained through what is termed 'negative' (or deviation attenuating) feedback, while 'positive' (or deviation amplifying) feedback tends to provoke system into unstable states. Typically these two types of forces are working concurrently; adding further to the 'tensions of difference'. Under certain circumstances, these tensions reach such a level that the whole system suddenly succumbs. As a consequence, it becomes destabilised and for a while acts quite 'chaotically'. This phase is often followed by an equally sudden restabilisation in a new, and frequently more complex form (Gleick 1988). These 'chaotic' transformations in organisation are also associated with emergent properties which are therefore also quite unpredictable from knowledge about the previous state of the system before its chaotic change. 
Such 'higher order' re-stabilisation does not always occur of course, in which case the system might either revert to its previous position or collapse altogether, following a chaotic episode.

From this discussion it is apparent that there are two sources of emergence in systems dynamics: Firstly between different levels within a 'stable' hierarchy (Figure 1a) and secondly, following a chaotic reorganisation to a higher order of complexity (Figure 1b).

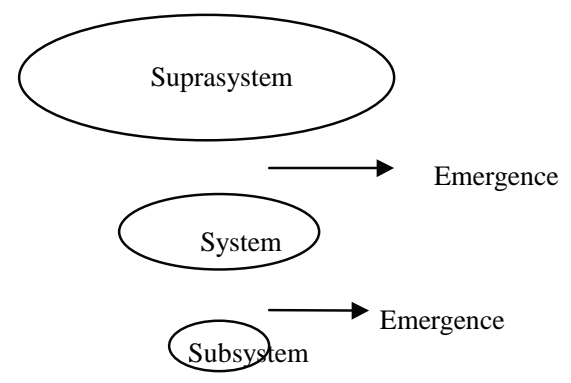

Figure 1a Emergence Between Levels of a Stable Systems Hierarchy

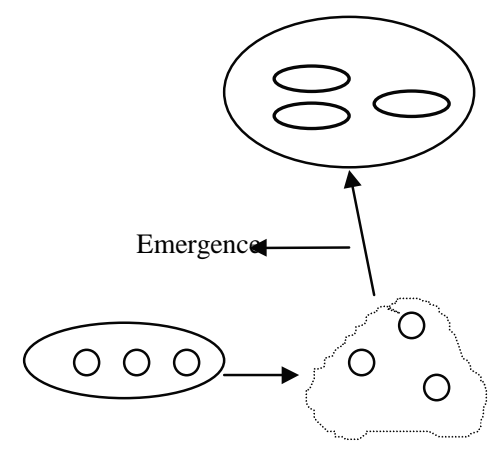

Figure $1 \mathrm{~b}$ Emergence as a Function of of Chaotic Disorganisation.

While these theories have been constructed from studies of physical systems, strong parallels can also be drawn with the behaviour of so-called social systems, whether they are viewed as such either 'in actuality' or metaphorically. In any event, all of these principles are of considerable significance to the concept and indeed model of a critical learning system, and they are also crucial elements in the notion of any learning community which is viewed from the perspective of systemic development. To view the world systemically is to view it from the perspective of systems, just outlined. Systemic worldviews are a prerequisite for treating the world in a systemic (holistic) way, and the ability to adopt such worldviews and transpose them into practice is not easy, as twenty years of experience at Hawkesbury has confirmed.

\section{A Justification for Critical Learning Systems: The Community Challenge}

A primary context for the work on critical learning systems at Hawkesbury, has been the growing concern that prevailing models of non-systemic development are significantly inadequate in the face of the dynamics, complexities and uncertainties of contemporary life. Early concerns about these models now find justification in the considerable empirical evidence of such matters as the increasing maldistribution of wealth (George and Sabelli 1994), the gross degradation of the bio-physical environment (Brown 1989), the loss of both cultural and biological diversity (Milbraith 1989), and a host of other factors reflecting the inadequacies of the prevailing theoretical paradigm which is characterised by "reductionism, determinism and autonomous individualism, all undergirded by a stringent materialism" (Vitz 1996). The force of these collective worldviews has been such as to contribute fundamentally to the often bemoaned 'loss of community' (Fukuyama 1995), with the lack of trust that has grown from this situation, now acting as a serious impediment to its restoration.

This lack of trust is even beginning to extend to the way development 'is done'.

Worse, we are in grave danger of falling victim to our own development 'successes' achieved through the technoscientific applications which reflect these prevailing worldviews. These have had widespread negative impacts as well as positive ones, and yet the process of development based on them, continues to remain relatively free from critique. We must now have a new focus, and there are those who believe that a new era is dawning: As the sociologist Ulrich Beck (1992) reminds us, "we are therefore concerned no longer exclusively with making nature useful, or with releasing mankind from traditional constraints, but also and essentially with problems resulting from techno-economic development itself". "Modernisation" he claims "is becoming reflexive; it is becoming its own theme". Technoscience has got to learn how to confront itself in a world where the risks 
flowing from technology-in-action have become global, and paradoxically, only knowable through the very same process through which they were generated. To be self-confrontational however, in the sense that Beck suggests, we will need to approach matters very differently. As Bruce Wilshire (1990) has stated, "we have powerful means of altering the earth and ourselves, but only a fix on goodness could give our means their aim, support and meaning". All of the major problematic issues raised above have ethical and aesthetic dimensions as well as instrumental ones, and the need for 'fixes on goodness', or moral judgements, thus becomes an imperative, in the face of a fundamental paradigmatic inadequacy: "Moral judgement has been eliminated from our concepts of rationality as far as they are actually built into existent scientific and systems paradigms" (Ulrich 1988).

The challenge then is to re-foster what might be a lost competency for what Edgar Dunn called 'social learning', and a second aspect of reflexivity is indicated here as: "the process of social learning has not understood itself sufficiently well to rationalise itself as an efficient process with a coherent purpose" (Dunn 1971). The quest for systemic development is essentially a learning process, which appreciates and accommodates its own complexity, in addition to that of the main problematical matters (of development) to hand. The central feature of the approach is therefore the design, establishment, maintenance and development of self-referential, or critical, learning systems.

In the terms of our critical learning system approach then, we need to facilitate the transformation of communities into learning systems which are sufficiently self-referential that they will be able to learn about their own learning.

\section{Meaning as an Emergent Property}

Important cues for the basic form and process of the Hawkesbury critical learning systems model are provided by the work of Victor Frankl (1963), Gregory Bateson (1978), and C.West Chuchman (1971), with ideas from Aristotle, the medieval cleric St.

Bonaventure, and Ken Wilber (1990) also as foundational.

The central notion here is that meaning is a property which is emergent in both individuals and communities, through the interactions of different 'ways of knowing'.

As we see it at Hawkesbury, meaning emerges as the result of 'interactions' between the process of experiential learning on the one hand, and what we have termed inspirational learning on the other with these processes in turn involving the concrete world of experience, the spiritual world of insights, and the abstract world of concepts at the interface (Figure 2).

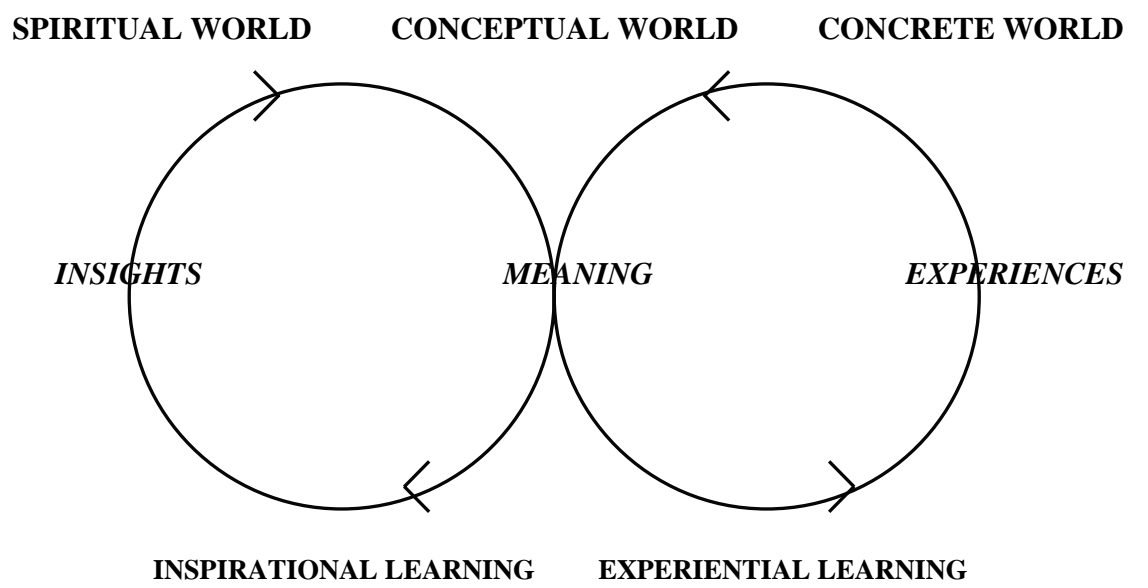

Figure 2 Meaning as an Emergent Property of Two Ways of Learning 
These ideas of the spiritual, the conceptual and the concrete are not that far removed from those mooted by Bonaventura, who, as Ken Wilber (1990) records, distinguished between an eye of contemplation ("by which we rise to a knowledge of transcendent realities), an eye of reason ("by which we obtain a knowledge of philosophy, logic and the mind itself"), and an eye of flesh ("by which we perceive the external world of space, time, and objects"). Wilber himself distinguishes between transcendelia, intelligibilia and sensibilia (Wilber 1990).

A key concept from Hawkesbury, is that this process can be re-presented in systems terms: Thus the experiential learning process can be envisaged as one subsystem within a learning system of two subsystems, with inspirational learning as the second. Each learning subsystem is itself a system with its own subsystems, and the model can be further expanded to illustrate the four sub(sub)systems in each (sub)system in a learning system, as illustrated in Figure 3.

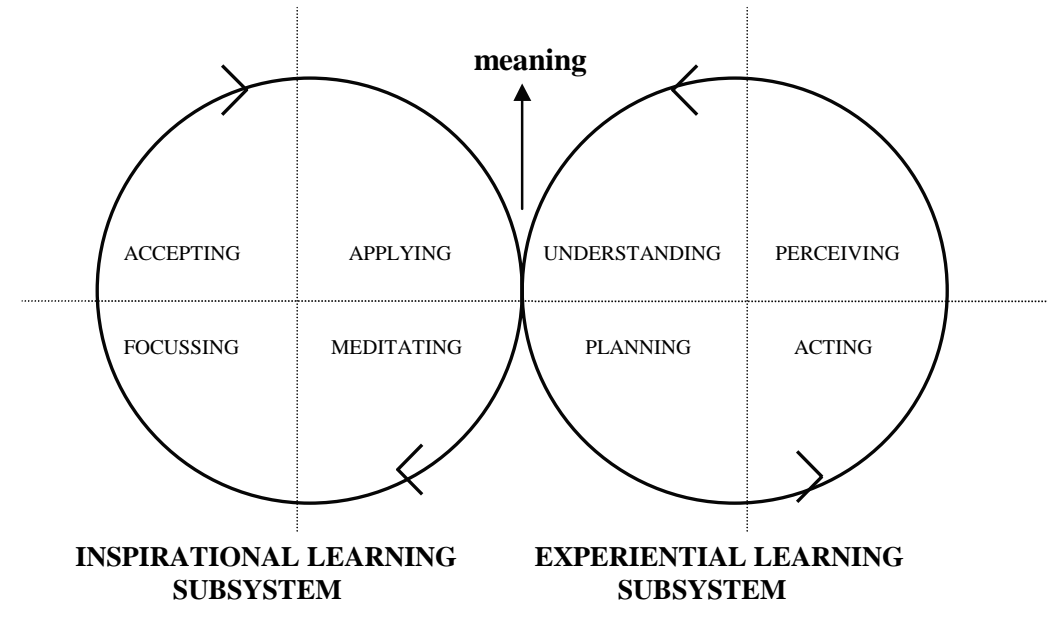

Figure 3 The Sub(sub)systems of a Learning System for Generating Meaning for Actions

As this model illustrates, a dynamic is established between the processes of experiential and inspirational learning, through which concepts derived from the transformation of experience are qualified by insights derived from inspirational learning in the creation of meaning as a prerequisite for responsible, systemic action.

\section{The Experiential SubSystem}

To understand the dynamics of such a system, and how it might be used as a model in practice, we need to explore these processes in more detail, and to do this, we turn first to the process of experiential learning, and to the work of David Kolb in particular.

Kolb (1984) suggests that learning is the creation of knowledge through the transformation of experience. He posits that the process occurs as a result of our need to reconcile two dialectic tensions that we feel as a result of two different ways through which we 'grasp' reality (through concrete experience or through abstract conceptualisation), and two ways through which we transform what we have grasped (through reflective observation or through active experimentation). He expresses these two dialectics as polar positions on a matrix, which he then converts into a cycle to illustrate the dynamics of the dialectic resolution (Figure 4).

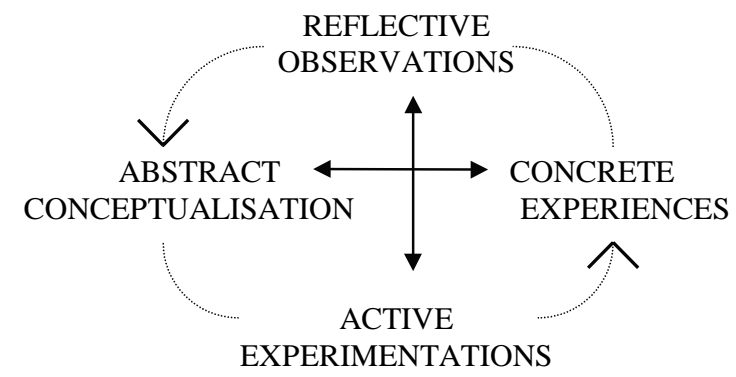


Figure 4 An Experiential Learning 'Cycle'

Kolb went on to argue that the complete experiential learning process thus involves the learner, in resolving the dialectical tensions between these two pairs of polar opposites, in four basic activities which he termed divergence, assimilation, convergence and accommodation respectively.

- divergence involves the learner moving from concrete experiences to reflective observations

- assimilation from reflective observations to abstract conceptualisation's

- convergence from abstract conceptualisation to active experimentations, and

- accommodation from active experimentations to concrete experiences

The essence of these four activities can be captured with the notions of perceiving as the act of divergence, understanding as assimilation, planning as convergence, and acting as accommodation (Figure 5).

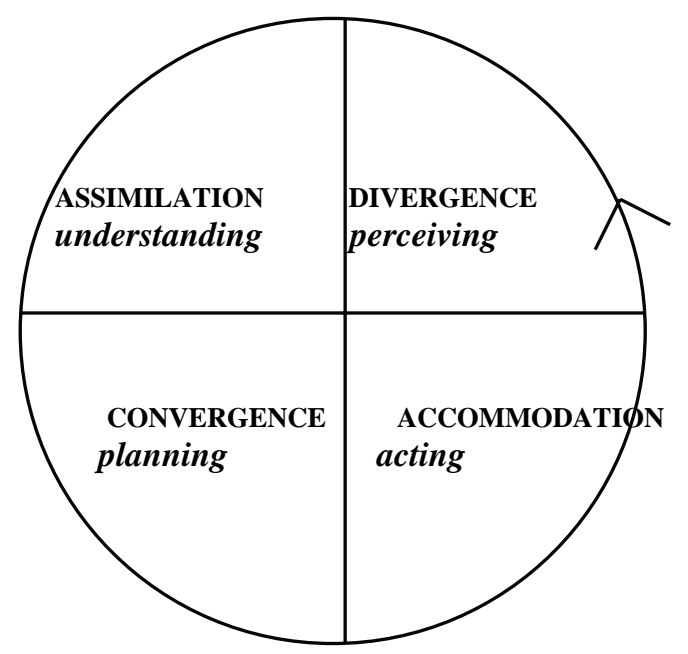

Figure 5 The Four Basic Activities in an Experiential Learning Process

Following Kolb, but using the language we have introduced, the process of experiential learning can be described in a highly simplified manner, in the following terms: The process of learning starts with the immersion of the learner in a concrete experience from which as many observations as possible are gathered and perceptions recorded. This stage of information gathering is then followed by a phase of thinking, during which attempts are made to understand what has been experienced - and sense is made out what has been sensed! This stage is followed, in turn, with plans for action based on the understanding achieved. Finally, the planned action is taken, and as this changes the situation, the whole process is repeated, and more knowledge created.

Experiential learning is thus a recurrent process of adaptation to change, based on a rigorous process of transformation.

In reality of course, this learning process is far less systematic than is being inferred here. Rarely do we conduct our learning with such discipline and rigour, and nor does all of learning start with 'immersion in a concrete experience'. Much of our learning (and virtually all of our formal education!) starts at the opposite pole, as we are immersed not in concrete realities but in preformed abstract conceptualisation's. Rarely do we therefore get the chance to test those ideas back in the concrete world, nor plan or take action as a consequence of what we have learned (save perhaps to feedback our understanding to the 'teacher' for a grading of our ability to understand, or at least remember). 
The first step towards the creation of a learning community - a critical learning system - is therefore the facilitation of consciousness of the process of learning itself: Learning to learn about learning. And this need for what has been termed meta-learning (Kitchener 1983), immediately adds a new and vital dimension to the learning systems model, which becomes a 'higher order' system within the learning systems hierarchy. Finally in this regard, a third 'level of learning', referred to as epistemic learning (Kitchener 1983), must now be added to provide the dimension of learning about the worldviews which contextualise what is being learned (Figure 6).

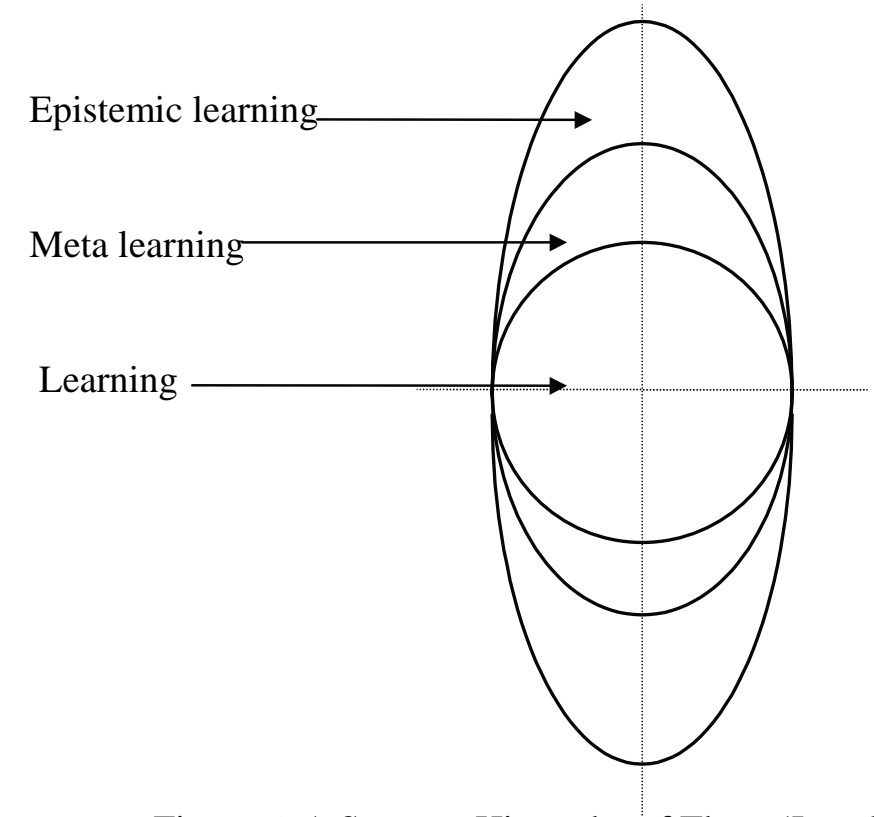

Figure 6 A Systems Hierarchy of Three 'Levels' of Learning

Speaking in terms of 'levels of cognitive processing', Kitchener herself describes these three levels as (a) cognition, which deals with knowing, (b) meta-cognition, which deals with knowing about knowing, and (c) epistemic cognition, which deals with knowing about the nature of knowledge. It is through epistemic learning that we learn to appreciate the nature of the worldviews and paradigms which we hold as the contexts for what and how we know, and also that we learn how to both challenge and, if appropriate, change them. It is at this level that we learn the implications of the prevalence of the worldview identified earlier as being based on the "reductionism, determinism, autonomous individualism, and materialism" (Vitz 1996).

\section{Worldviews}

To help us help learners to explore this domain, we have, introduced an icon to depict worldviews, again in the form of dialectics. Drawing on ideas introduced by Burrell and Morgan (1979) and Miller (1983), we have developed the notion of a worldview matrix composed of an ontological dimension (as the polar positions of holism on the one hand and reductionism on the other) and an epistemological dimension (with the polar positions of objectivism on the one hand and relativism on the other). As we see it, where ontologies are concerned with beliefs about the 'nature of nature', epistemologies concern themselves with the 'nature of knowledge' (about the nature of nature!). The distinctions in ontology recognised here, reflect the idea that one either accepts the irreducible wholeness of nature and other systems (holism), or one does not (reductionism). With respect to the epistemological distinctions one either accepts that there is "a permanent, ahistoric matrix or framework to which we can ultimately appeal in determining the nature of rationality, knowledge, truth, goodness or rightness" (objectivism) - as Bernstein (1983) put it - or we do not (relativism). We present each of the four quadrants as particular worldviews or 
paradigmatic positions, and have labelled them according to the idea of the specific focus or 'centricity' of each (Figure 7).

Given that our worldviews, as represented here at least, reflect our most fundamental belief positions, it is not at all surprising that we hold to them with such conviction. It is equally understandable that communication between people with different worldviews, is typically so distorted.

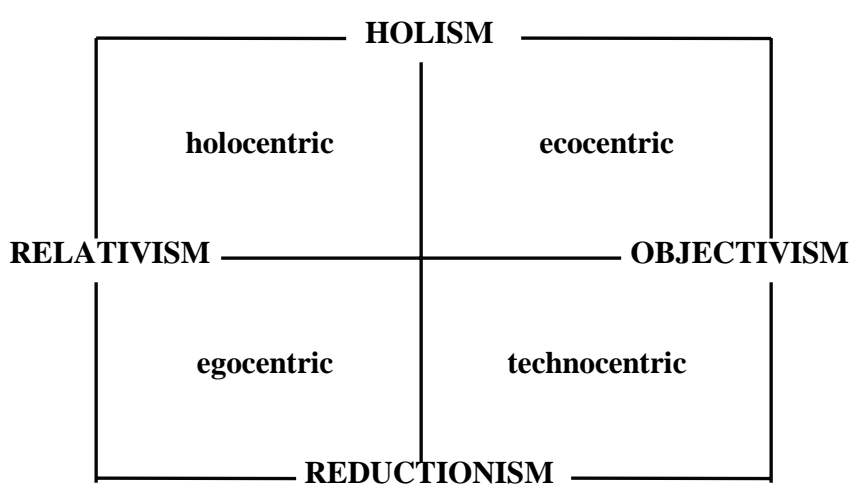

Figure 7 Four Worldviews as Functions of Differing Ontological/Epistemological Positions

The technocentric view of the world, which from the earlier comments can be taken as representing the prevailing paradigm of modernisation, is as far removed from the holocentric view as is conceivable to imagine, on this model. It is not surprising that the discourse about what constitutes responsible community development, for instance, is so difficult, given the tensions that exist between different belief positions and thus worldviews. A critical learning process must therefore include discourse about the nature and influence of worldviews on the process of learning - and ultimately, on development itself?

Our worldviews are not limited to cognitive belief positions but also extend to include normative positions, which are grounded in values frameworks. A similar form of matrix to the cognitive worldview framework can also be used to express different normative positions, although in this instance the situation is more complex as a function of the very nature of values. To illustrate the possible dimensions of a 'value framework', we have chosen two dimensions of the 'good society' that many claim to be at the core of our civilisation: Following James O'Toole (1993) we can thus discriminate between libertarianism and egalitarianism as one dialectic tension, and between corporatism and communitarianism, as the other (Figure 8).

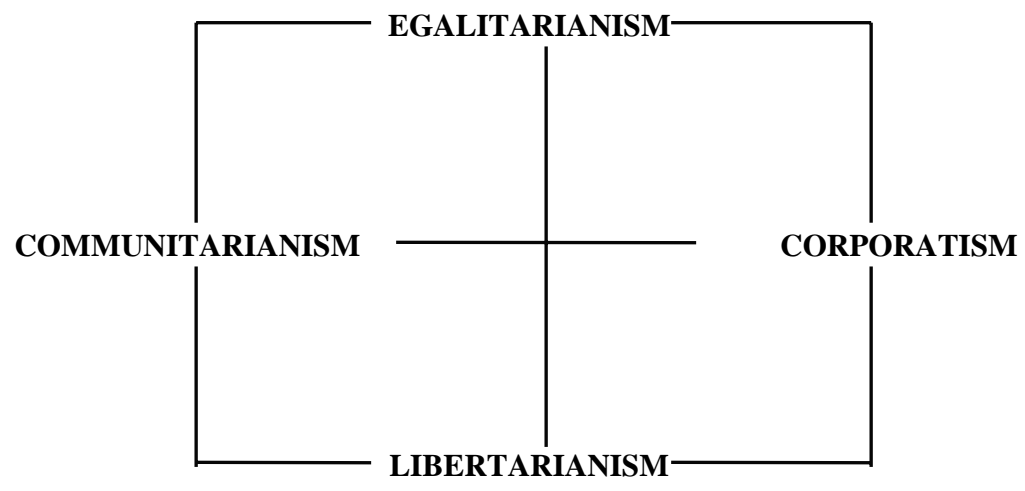

Figure 8 A Normative Worldview Window 
These normative dialectics are of course different from their cognitive counterparts in that they only express themselves as 'polar opposites' when taken as extreme positions. The four cells furthermore, remain unlabelled, as the notion of centricity is also less apposite here. The point remains however that we do hold views which are markedly influenced by the particular normative positions we take on matters related to our respective dreams of the 'good society' and on liberty, equality, efficiency and community, which, as O'Toole (1993) submits "tug like polar forces....at the society as a whole" and where "these four great themes of political argument are tradeoffs with each other, zero-sum positions in which an increment of one value leads to a consequent equivalent loss of its opposite". Again it must be emphasised that these dimensions, fundamental that they are, represent but a fraction of the total value positions which we bring to bear in any discourse about development.

The issue here is that normative elements are as basic to the worldviews that we hold as are cognitive elements, and that awareness and critical consciousness of them are necessary perquisites for the 'emergence of meaning' from any learning system.

And it is through talking about values that we are inevitably led from the experiential focus to what we can sensibly call the inspirational focus.

\section{The Inspirational SubSystem}

While the British science writer C.P. Snow (1959) certainly popularised the notion of the 'two cultures', with the reason of the sciences on the one hand and the aesthetics of the arts on the other, the recognition that being human is much more than being objectively rational, stretches back at least to the time of the ancient Greek civilisation. The clear distinction which Aristotle made between the episteme on the one hand, and nous on the other, was a theme which persisted to the eighteenth century of Immanuel Kant - with his concern for the relationships between the facts and principles of science, and ethics and moral discourse - and beyond. Indeed today, there persists a distinction within philosophy between those who judge right from wrong solely on the consequences of actions, and those who focus on the theory of natural law or on notions of natural rights (Singer 1994).

The principle of inspirational learning draws its logic from the time-honoured distinction between learning from 'outer experiences' on the one hand, and from 'inner insights' on the other: The spirit of being human if you will - hence the use of the word spiritual below. It is accepted that just as experiential learning draws its dynamics from the dialectics of two opposing ways of grasping reality and two opposing ways of transforming it, so a similar proposition can be raised concerning two opposing sources of understanding (concepts and insights) and two opposing ways of transforming them (contemplation and application).

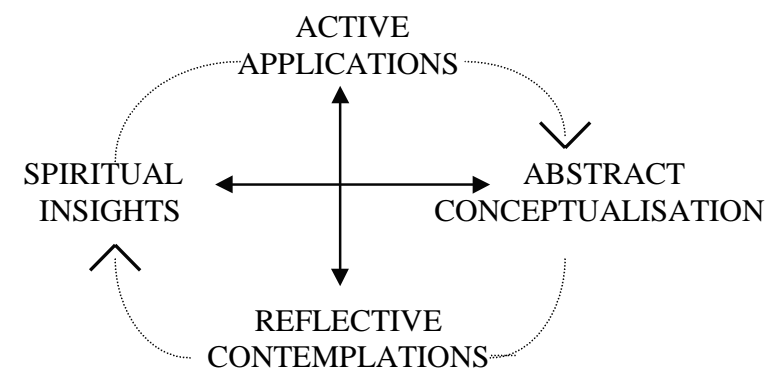

Figure 9 An Inspirational Learning 'Cycle'

In a manner analogous to the experiential process of Kolb (1984), and drawing on notions developed by Francisco Varela and his colleagues (1992), Ken Wilber (1990), and a lifetime's reading of poetry and listening to great music, the following four domains can be 
tentatively proposed as appropriate to a process of inspirational learning: disengagement, accession, appreciation, and enactment (Figure 10).

- disengagement involves the learner moving from abstract conceptualisation's to reflective contemplations

- accession from reflective contemplations to spiritual insights

- appreciation from spiritual insights to active applications, and

- enactment from active applications to abstract conceptualisations.

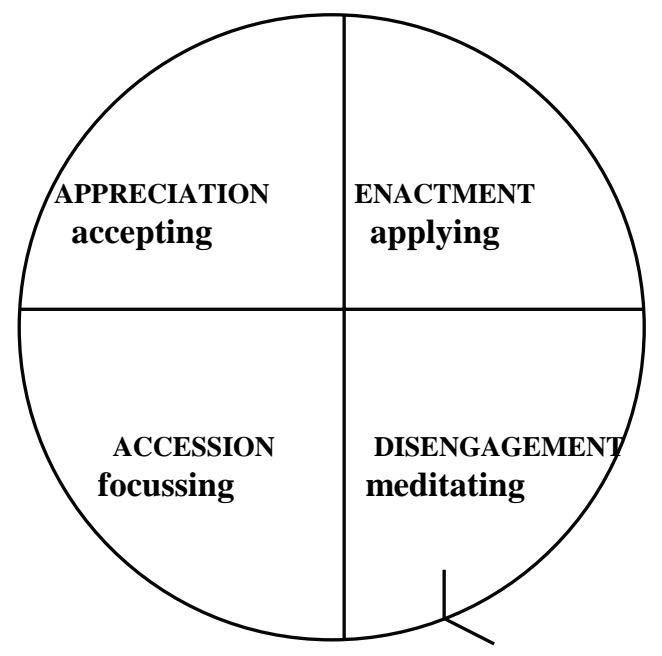

Figure 10 Four Basic Activities in an Inspirational Learning Process

Again following Kolb, but using the new language just introduced, the process of inspirational learning can be described in the following way:

The process of learning starts with the disengagement of the learner from the conceptual world through some process akin to meditation, in order to allow the mind to free itself from thoughts and enter a state of self-awareness with compassion. This stage is then followed by an attempt to 'focus' on one's innermost being and on the insights that are either 'held' there or are created through the process of introspective contemplation. The third stage involves the learner in accepting the insights that have been revealed during the previous stage, while the final phase sees the application of these insights into the process of meaningmaking.

Meaning emerges from the 'systemic' interaction of insights gained through inspirational learning with abstract concepts learned through experiential learning.

Earlier it was submitted that the experiential process, when regarded as a learning system, could be envisaged as a system within a three 'level' systems hierarchy which also involved meta and epistemic dimensions. Following the same logic, it is tempting to suggest a similar situation with respect to inspirational learning. However, given the deliberate rejection of 'rational' analysis within the latter process, it is probably not relevant to speak in these hierarchical and rational terms with reference to the inspirational learning process. It is appropriate however, to incorporate the values-based worldview into the process, reflecting the notion that just as there is an important relationship between the cognitive framework and the generation of meaning in the experiential learning system, so too can one defend the probability of the significance of a normative framework influencing the process of insight 'creation' or 'revelation'. 


\section{The Integrated System}

We are now almost in a position to integrate all that as been discussed into a complete model of a critical learning system, which has, in turn, practical application as a 'road-map' for the design, maintenance, development and evaluation of 'learning communities'. There are just two further aspects to the system that require addition and explanation, and they relate to the matters of emotion and of power. It has long been recognised that emotions not only affect the process of learning, but can be harnessed by it; to advantage. Aristotle put it this way: "anyone can become angry - that is easy. But to be angry with the right person, to the right degree, at the right time, for the right person, and in the right way - this is not easy." The source of this quotation is a recent book by Goleman (1996) on what he terms emotional intelligence. The point that he makes and both defends and extends, is that as emotions very significantly influence the way we learn, it is sensible to learn how to use them to our advantage. From the perspective of a learning system, we might envisage emotions such as anger, sadness, fear, enjoyment etc, as constituting important environmental 'elements' both within the system (as its ambience), and beyond it, in the environment at large. The intelligent learner both recognises and manipulates these environment to advantage in the construction of meaning.

And this brings us to the final issue of power, and its influence, as Habermas (1984) has emphasised, as a potential source of distortions in communication, and thus on learning. This is not the place to elaborate on this complex matter, save to recognise that it too, needs to be focus of critical reflection, and central to any self-referential learning system.

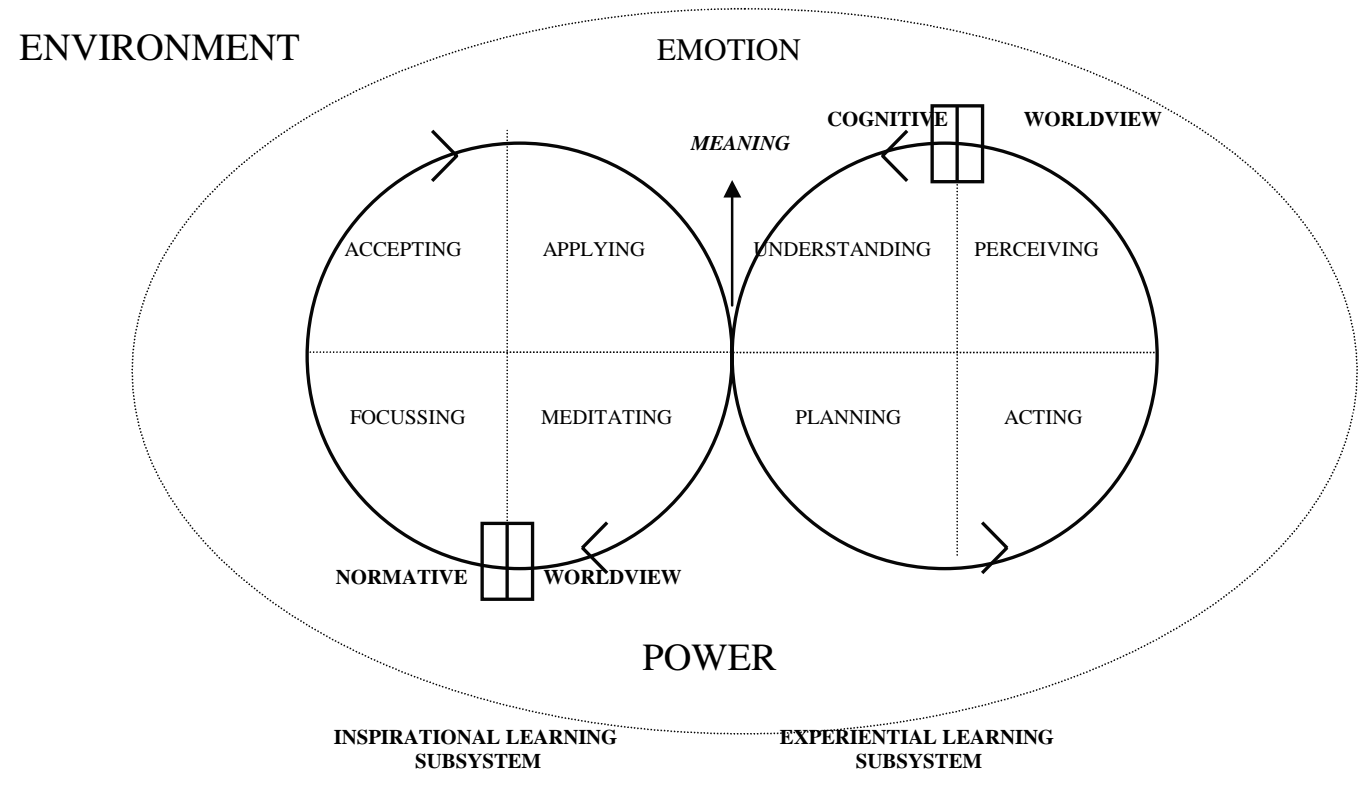

Figure 11 The Integrated Critical Learning System

\section{Practical Application}

As with any conceptual model it is vital to remember that the "map is not the territory'. The image of the critical learning system above is just that: An image, a mental construct, which has been generated through the application of theory and insights to help create meaning from real world experiences, which have in turn, helped in the modification of those theories and the creation of fresh insights. So this is as much an illustration of what some of us see as the process of community learning that has characterised initiatives at Hawkesbury over the past two decades, as it is an idealised image of what we believe describes a generalised model of a critical learning system. 
In its application, it suggests a series of important factors to consider whenever the establishment, development and evaluation of a learning community is being mooted. It illustrates a number of key aspects of 'social learning' indicating some of the domains and dynamics that need to be considered. These are worthy of review under the rubric of an effective learning community as one which:

- Has achieved a sense of its own coherence and integrity

- Contains a requisite level of variety and diverse tensions of difference which are essential for its own dynamic

- Is clear about its purpose and the influence of this on the boundary of its concerns and indeed its structure

- Combines both experiential and inspirational learning processes in its quest for meaning for responsible action

- Is conscious of meta and epistemic cognition, and of the influence of both cognitive and normative worldviews as frameworks for the way meaning is created

- Is critically aware of its own emotional ambience, and competent at the intelligent management of those emotions

- Is aware of the emergence of properties unique to different levels of its own systemic organisation, just as it is to the dynamics of chaotic change and the potential of property emergence following reorganisation

- Appreciates the nature of the environments (suprasystems) in which it operates, and is conscious of both constraining and driving 'forces' in that environment

- Is critically conscious of its own power relationships and those which exist between it and the environment about it, and knows what influence this has as a potential distorter of communication

- Is self-referential, critical of its own processes and dynamics, and capable of selforganisation in the face of continual challenge from its environment

- Exhibits leadership as well as meaning as an emergent property

This 'checklist' of systems' characteristics provides a framework for the sort of conversations and discourse which guide a community which is intent on improving its own capacities for learning its way into better futures.

It is a map for systemic development which has its own continuing systemic development.

\section{Dedication and Acknowledgments}

This presentation is dedicated to the memory of Diane, who, in learning how to die, provided an infinite source of insights into learning how to live.

As always it is a privilege to acknowledge the generations of learners who have been, as many continue to be, participants in Hawkesbury's grand enterprise, whose experiences, concepts and insights have both helped in the evolution of the model, and been informed by it in their own extensive activities in the facilitation of learning communities. Among my academic colleagues, I would specifically like to acknowledge the support of Bruce McKenzie, Roger Packham and Bob Macadam as together we attempt to create a new critical learning system at the Centre for Systemic Development.

\section{References}

Ackoff, R. L. (1981) “Creating the Corporate Future” Wiley New York 
Bateson, G. (1978) "Steps to an Ecology of Mind" Paladine London

Bawden, R.J. (1992) "Systems Approaches to Agricultural Development: The Hawkesbury Experience" Agricultural Systems 40: 153-176

Bawden, R.J. and Packham, R.G. (1993) "Systemic Praxis in the Education of the Agricultural Practitioner" Systems Practice $\underline{6}:$ 7-19

Bawden, R.J., Macadam, R.M., Packham, R.G., and Valentine, I (1984) "Systems Thinking and Practices in the Education of Agriculturalists" Agricultural Systems 13: 205-

225.

Beck, U. (1992) “Risk Society: Towards a New Modernity" Sage Publications London

Bernstein, R.J. (1983) “Beyond Objectivism and Relativism” University of Pennsylvania Press

Bertalanffy, L. von (1968) "General Systems Theory” Braziller New York

Brown, L. (1989) "State of the World" (series) Worldwatch Institute Allen and Unwin London

Burrell, W.G. and Morgan, G. (1979) "Sociological Paradigms and Organisational Analysis" Heinemann London

Churchman, C.W. (1971) “The Way of Inquiring Systems" Basic Books New York

Dunn, E.S. (1971) "Economic and Social Development: A Process of Social Learning” John Hopkins University Press Baltimore

Frankl, V. (1963) “Man’s Search for Meaning” Simon and Schuster New York

Fukuyama, F. (1995) “Trust” The Free Press New York

George, S. and Sabelli, F. (1994) "Faith and Credit: The World Bank's Secular Empire" Westview Press Boulder

Gleick, J. (1988) “Chaos: Making a New Science” Heinemann London

Goleman, D. (1996) “Emotional Intelligence” Bloomsbury London

Habermas, J. (1984) “The Theory of Communicative Action" Vol 1 Heinemann London

Kitchener, K. (1983) "Cognition, Meta-cognition, and Epistemic Cognition: A Three Level Model of Cognitive Processing" Human Development 26: 222-232

Kolb, D.A. (1984) “Experiential Learning: Experience as the Source of Learning and Development" Prentice Hall New Jersey

Laszlo, E. and Laszlo, A. (1997) "The Contribution of the Systems Sciences to the Humanities" Systems Research and Behavioural Science 14: 5-19 
Milbraith, L. (1989) “Envisioning a Sustainable Society” SUNY Press New York

Miller, A. (1983) “The Influence of Personal Biases on Environmental Problem-solving" Journal of Environmental Management 17: 133-142

O’Toole, J. (1993) "The Executive's Compass: Business and the Good Society" Oxford University Press Oxford

Singer, P. (ed) (1994) “Ethics” Oxford University Press Oxford

Snow, C.P. (1959) "The Two Cultures and the Scientific Revolution" Cambridge University Press Cambridge

Ulrich, W. (1988) "Systems Thinking, Systems Practice and Practical Philosophy: A Program of Research" Systems Practice 1: 137-163

Varela, F.J., Thompson, E. and Rosch, E. (1992) “The Embodied Mind” MIT Press Cambridge

Vitz, P.C. (1996) "Back to Human Dignity: From Modern to Postmodern Psychology" The Intercollegiate Review 31: 15-23

Wilber, K. (1990) "Eye to Eye: The Quest for the New Paradigm" 2nd edition Anchor /Doubleday New York

Wilshire, B. (1990) "The Moral Collapse of the University: Professionalism, Purity and Alienation" State University of New York Press 